\title{
东亚大城市菜市场发展经验及其借鉴 以中国香港、中国台湾和新加坡为例
}

\author{
Learning from Wet Market Development in East Asian Metropolis: \\ Cases of Hong Kong, Taiwan Districts and Singapore
}

摘要: 针对中国大城市在菜市场转型过程中遇到的规 划、设计和管理方面的问题, 本文以中国香港、中国 台湾和新加坡为例, 通过文献收集和实地调研等方法, 在梳理三地菜市场发展历程的基础上, 对其规划布局、 建筑设计和管理机制进行分析比较, 进而对中国菜市 场转型提出可资借鉴的发展思路和对策建议。

Abstract: In China's metropolis, wet markets are challenged in planning, design and management during the transition period. In this paper, three East Asian metropolis, namely Hong Kong, Taiwan Districts and Singapore, are chosen for case studies. Based on the introduction of wet markets development process, the paper analyzes the measures in facility planning, architecture design and management mechanism, and finally discusses their implications for China.

关键词：菜市场；转型；更新；东亚

Keywords: Wet Markets; Transition; Renewal; East Asia

国家社会科学基金项目（16CRK020），教育部人文 社会科学研究青年基金项目 (15YJCZH016), 北京 市社会科学基金项目 (15SHC043), 北京市优秀人 才培养资助项目（2016000020124G082）
作者: 吴洁琳, 清华大学建筑学院硕士, 广州市城市 规划勘测设计研究院助理规划师。 wjlxbd@qq.com 陈宇琳 (通信作者), 清华大学建筑学院, 副教 授。chenyulin@mail.tsinghua.edu.cn

\section{引言}

近年来, 在我国城镇化快速发展和菜市场从国营向私营转型的背景下, 菜市场的生存和发展面临诸多挑战。在旧城区, 由于菜市场利润较低, 随着 地价快速上涨, 菜市场空间受到严重挤压 ${ }^{[1]}$, 而随着菜市场承担的服务人口 越来越多, 又带来菜价高、买菜难等问题 ${ }^{[2]}$ 。在新建居住区, 由于菜市场用 地在现行居住区规划规范下得不到保障, 在实际使用中又多被其他高收益用 途侵占, 导致菜市场配套严重不足 ${ }^{[3]}$ 。这不仅影响了城市居民生活的便利, 同时也阻碍了外来商贩的市民化道路 ${ }^{[4,5]}$ 。

针对我国大城市在菜市场转型过程中遇到的规划、设计和管理方面的问 题, 本文选择东亚的中国香港、中国台湾和新加坡三个地区进行案例研究。 在西方, 食物消费习惯通常随着经济发展而改变; 然而在新加坡、中国香港、 中国台湾等地, 尽管人们去超市很方便, 但日常购买蔬菜水果和鲜肉仍然热 衷于去菜市场 ${ }^{[6]}$ 。这三个地区的经济较为发达, 围绕菜市场转型的城市规划 建设和管理有较长的历史并日趋成熟, 菜市场不仅是城市居民日常生活重要 的公共服务设施, 甚至成为当地文化的一部分。

本文将在梳理三地菜市场发展历程的基础上, 按照 “规划布局一建筑设 计一管理机制” 的分析框架加以阐述 : 在规划布局方面主要关注用地权属、 设置标准和规划选址, 在建筑设计方面重点分析建筑形式、功能构成和环境 设计, 在管理机制方面侧重探讨政府管理模式以及政府与市场、社会的关系。 本文旨在通过对中国香港、中国台湾和新加坡三地规划设计原则和建设管理 经验的总结, 对我国大城市菜市场转型提供可资借鉴的发展思路和对策建议。

\section{1 香港经验}

菜市场在香港称为 “街市” (street market), 是香港居民日常生活的重要 商业设施, 2009 年, 香港居民在传统街市购买食物的比例高达 $74 \%{ }^{[7]}$ 。香港 街市主要由食品环境卫生署、房委会和私人企业管理, 前两者管辖的又被称 为 “公众街市”。目前食物环境卫生署下辖 100 多个公众街市, 提供 14400 个推位; 房委会下辖 21 个公众街市。公众街市售卖新鲜粮食、熟食、衣物 以至家庭用品等多类货品; 推档面积由 $1.2 \sim 70 \mathrm{~m}^{2}$ 不等; 租金采取投标的形式, 
年满 18 岁并通常居于香港的人士 ${ }^{1}$ 均可竞投, 租金从上百 元至数万元不等, 合约期一般为三年 ${ }^{[8]}$ 。街市开放时间一般 为每日早上 6 点至晚上 8 点。

\section{1 发展历程}

1841 年开埠前, 香港以自给自足的自然经济为主。英 国管治港岛后, 引人街市制度。出于整治公共卫生环境的目 的, 1929 年通过的《公共卫生与建筑物条例》修订案确定 了洁净局管理街市的法定权力。 20 世纪 60 年代一 90 年代是 香港大量建设公众街市的阶段。由于旧区人口密度增加, 新 城蓬勃发展, 为满足社区居民购买新鲜食品的需求并解决交 通环境等问题, 香港市政局及区域市政局设计兴建了标准型 街市, 以提供水、电等基础设施。

然而, 随着公众街市的快速建设, 2008 年香港公众街市 开始出现高成本和高空置率的问题 ${ }^{[9]}$, 食物环境卫生署为此 采取了撤市、丰富业态、改造活化等措施。2009 年以来, 由 于香港政府认为社区超市和便利店即可满足食物购买需求, 而新建和运营街市的成本又较为高昂, 至今没有建设新的街 市, 但有关部门也表示会根据需要新建街市。

在香港街市的发展历程中, 2004 年的私有化尝试是一 次重大变化。由于 1997 年亚洲金融风暴的影响和“八万五 建屋计划” 的停滞, 房委会严重赤字 ${ }^{[10]}$, 遂把下辖的 80 个 街市（占当时街市的 44\%) 出售给领汇房地产信托投资基 金会 (后文简称领展)。领展接管后提出街市改建商场计划 并引人超市化经营模式, 这一做法虽然实现了高效、整洁 的目标, 但也带来食材种类不全、缺乏人情味、摊位租金 上涨、档主经营艰难等问题, 与街市建设初衷相悖 ${ }^{[11]}$ 。为 此不少人提出 “香港街市的私有化实验是失败的” ${ }^{[12]}$, 近 年来香港每逢大型游行, “回购街市” 的呼声都此起彼伏。 对此, 香港消费者委员会认为当时应设置试验期, 在街市 所有权转换时附加条件限制领展的行为, 以保证零售市场 的充分竞争 ${ }^{[13]}$ 。

\section{2 规划布局：从量化到弹性的规划标准}

为实现满足居民购物需要和提供社区就业机会的目标, 香港街市的规划标准经历了多次变革。在街市从 “以街为 市” 到转为室内街市的建设初期, 主要考虑的因素是安置小 贩集中管理, 因此档位规模由周边地区需要迁置的小贩数
量决定。在 1990年出台的《香港规划标准与准则》中, 为 了更好地服务周边居民，关注点从“供”转向 “需”，提出 新建街市档位应参考家庭户数或总人数按比例设置, 要求 每 55 65 户家庭设有一个公众街市档位, 或每万人设有约 40 45 个档位, 市场规模一般为 $1000 \sim 3000 \mathrm{~m}^{2}$ 。在经历了 街市快速建设并出现空置情况后, 于 2009 年修订的《香港 规划标准与准则》则强调零售设施规划应由市场主导, 应用 规划标准时应具弹性, 需要按个别情况综合考虑人口构成、 社区需要、附近设施等确有需求再兴建。例如房屋署表示 如果公共屋邨较具规模而附近无类似设施, 就会考虑兴建 街市 $^{[14]}$ 。

\section{3 建筑设计 : 多功能街市大厦}

在用地紧张的情况下, 香港街市的建筑形态采用街市大 厦的形式。1979 年启用的鹅颈街市是现代化混合用途的街 市大厦, 此后新建的公众街市多根据社区需要和发展规划等, 结合市政大厦（相当于社区中心）设置，提供一站式公共服 务, 以提高便利性、服务效率及土地使用价值。街市大厦可 容纳熟食中心、市政办公、社区康乐、公共图书馆、幼儿园 和停车场等功能, 这种安排尤其受老年人欢迎, 购菜、办事、 锻炼和会友都十分方便（图 1)。

\section{4 管理机制：职责分明协作管理}

香港街市采用多部门协作的管理模式，各部门间职责明 确, 且形成监察审核机制, 避免因职责不清或者重叠导致管 理缺位。其中, 以食品环境卫生署和房委会为主, 管理各自 下辖街市的摊档租赁、清洁等日常事务; 海关、审计署等部 门从卫生、经营等方面实施监管; 市区重建局则负责改造、 活化和兴建工作, 以应对部分街市面临的设备老旧、客流减 少等问题。在改造过程中, 采取议员、街坊邻居和专家学者 多方参与的方式, 以达成价值共识。例如, 在中环街市活化 项目中, 由政府主导, 在项目策划、初步设计和深人设计等 阶段进行了多次民意调查, 并成立社区咨询委员会为项目建 言献策，最终确定了“创造闹市中的开放空间” 的活化目标 和保育价值等内容; 而嘉咸街改造项目则是民间自发推动 的一由关注社会问题的议员和热心的社会活动家发起, 带 动居民一起, 争取在房地产开发时预留足够的档位, 以保存 共同回忆, 并保护处于弱势地位的摊档主的权益 ${ }^{[15]}$ 。

(1) 有关“通常居于香港”的定义参阅“入境条例” (第 115 章) 第 2 条。香港政府给出的解释是：“如果你是合法、自愿和以定居为目的在香 港居住 (例如读书、工作或居留等) , 不论时间长短, 你会被视为通常居住在香港。”连续七年“通常居于香港”才有资格申请成为香港永 久性居民。 


\section{2 台湾经验 ${ }^{1}$}

在台湾, 零售市场即指传统零售 (菜) 市场 ${ }^{2}$ 。对外来 游客而言, 逛市场是了解台湾进而体验中华美食文化的好途 径。台湾的零售市场包括公有和民有两种，后期设立的摊贩 临时集中区的日市也属于零售市场范围。2010 年, 台湾共有 615 家公有零售市场 ${ }^{[16]}$ 。

\section{1 发展历程}

清朝时期, 台湾并没有针对市场的规划与管理, 居民在 街道和市集的摊贩处购买生鲜食品和日常用品。日据时代, 日本政府积极推动零售市场的规划和建设，1908 年建成第一 座公有市场, 1921 年即有相关条例出台。当时全台湾有 200 个以上的公有和私有零售市场 ${ }^{[17]}$ 。

1945 年后, 国民政府沿用日据时代市场政策。随着“都 市计划法” 的完善, 由政府规划、兴建与辅导零售市场的机 制逐渐形成。与此同时，政府也制定 “奖励投资与兴建公共 设施办法”，鼓励民间利用 “市场” 用地兴建市场 ${ }^{3}$ 。2 20 世 纪 70 年代末是零售市场发展的鼎盛时期, 零售市场成为居 民购买生鲜食品最主要的场所。

20 世纪 80 年代以来, 日据时代的市场建筑逐渐老旧, 伴随着居民消费要求提高, 零售市场进人现代化的重建阶段。 1985 年, 台北市政府允许既有摊贩集中区段成立推贩临时集 中区, 收纳推贩以改善地方交通及环境。为了保留传统市场
的人情味同时提升公有市场的整体形象, 政府分别于 2007 年和 2009 年出台了 “整洁明亮的传统市场新风貌再造计划” 和“传统零售市场更新改善计划”。

\section{2 规划布局 : 划定市场用地}

1954 年由台湾内政主管部门主导, 在全台乡镇地区划 定城市规划范围，不久即在制度上将 “市场” 列人城市规划 “公共设施”的范畴。1973 年第二次修正的 “都市计划法” 第四十二条明确提到 “市场” 用地, 第四十六条提出设置标 准 “应按问邻单位或居民分布情形适当配置之”。早期经济 发展水平低, 私人兴建成本过高, 把市场划人 “公共设施” 有利于政府依法编列预算兴建市场。发展至今, 随着零售市 场逐渐饱和, 在政府主导体制下菜市场的规划设计出现了无 法及时满足消费者新需求的问题, 一些学者建议应重新审视 市场划归 “公共设施” 和划定市场用地的必要性 ${ }^{[18]}$ 。但在 2015 年 “都市计划法”修正案中, “市场”用地仍被保留。

\section{3 建筑设计 : 现代综合楼和精细化设计}

20 世纪 80 年代以来, 台湾进人零售市场更新改造时 期, 为了整合市场与其他邻里生活设施, 改建主要采用 3 4 层的现代综合楼形式, 通风、排水、照明、冷藏设施和推 位安排等得到大幅改善。市场多安排在一、二层, 面积 $1000 \sim 2000 \mathrm{~m}^{2}$; 三、四层则设置市场办公室, 并结合社区 活动设置老人文康中心等, 成为社区的交往中心（图 2, 图 3)。
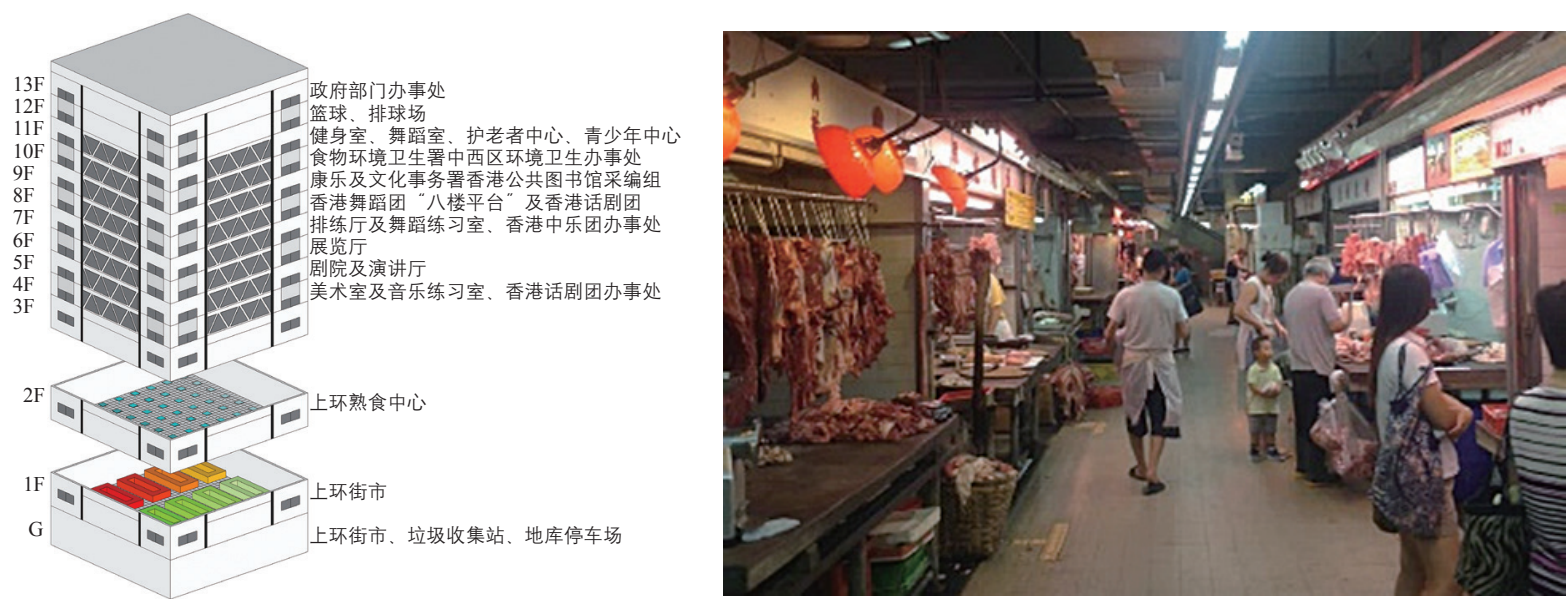

图 1 香港上环市政大厦

资料来源 : 左图由作者绘制，右图由陈明溓拍摄

(1) 由于台湾菜市场政策的制定多以整个台湾为范围, 因此本文以台湾为研究对象, 但在具体案例分析时主要关注台北经验。一是由于本文重点关 注大城市菜市场在转型过程中遇到的问题, 二是固于资料限制, 难以覆盖台南或其他中小城市等不同地区。

(2) 在 2007 年实行的《零售市场管理条例》将零售市场界定为“经直辖市或县 (市) 主管机关核准, 于都市计划市场用地或非都市土地之甲、乙、 丙种建筑用地, 以零售及划分推（铺）位方式, 供蔬、果、鱼、肉类及其他民生用品集中零售之经营场所。”

(3) 民有零售市场的兴建者需准备运营计划、市场规划等，向市场所在地的直辖市或县（市）主管机关申请核准。 
虽然零售市场经改造后面貌焕然一新, 但仍有一些市场 出现衰退趋势, 零售市场平均空推率超过 30\% ${ }^{[17]}$ 。这其中既存 在家庭消费习惯改变、市场停市改造过程导致顾客流失, 以及 流动商贩不公平竞争等外部原因, 也存在设施内部无法契合使 用者需求等问题。为此, 台湾在市场改造过程中提出精细化的 设计策略, 如优化档位设计和动线组织, 市场尽量避免设置在 二层以方便年长家庭妇女到达 ${ }^{[17]}$; 并且开始在改造过程中注 意采取过渡措施, 对商贩进行妥善安排, 避免顾客流失。不 仅如此, 为了振兴零售市场, 各地政府还积极举办文化活动。 如台北市政部门从 2008 年开始举办 “台北传统市场节”, 推出 “逛菜市场是台湾人的 style” 等理念, 以“既有大型超市的优 良购物环境, 又保有传统市场的热忱” 为目标 ${ }^{[19]}$, 改变菜市 场脏乱差的固有印象, 吸引更多的年轻人走进零售市场。

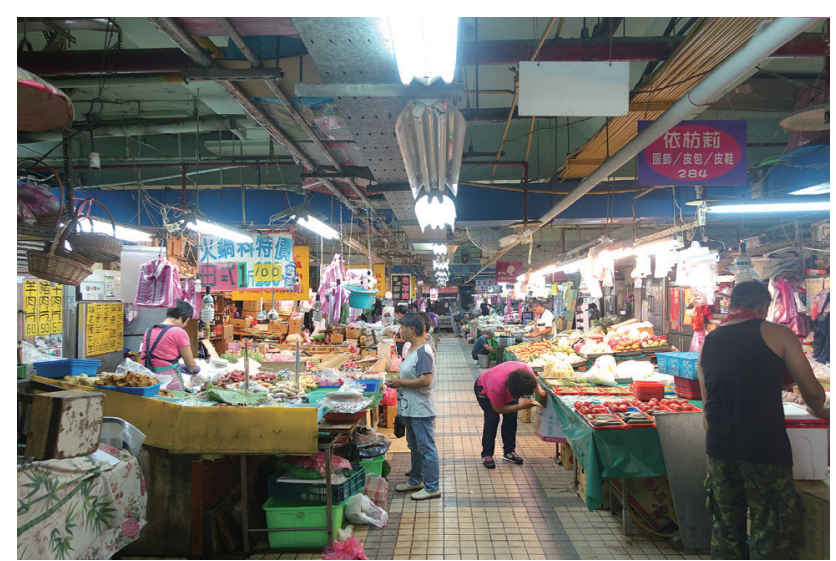

图 2 台北北投市场

资料来源 : 作者拍摄
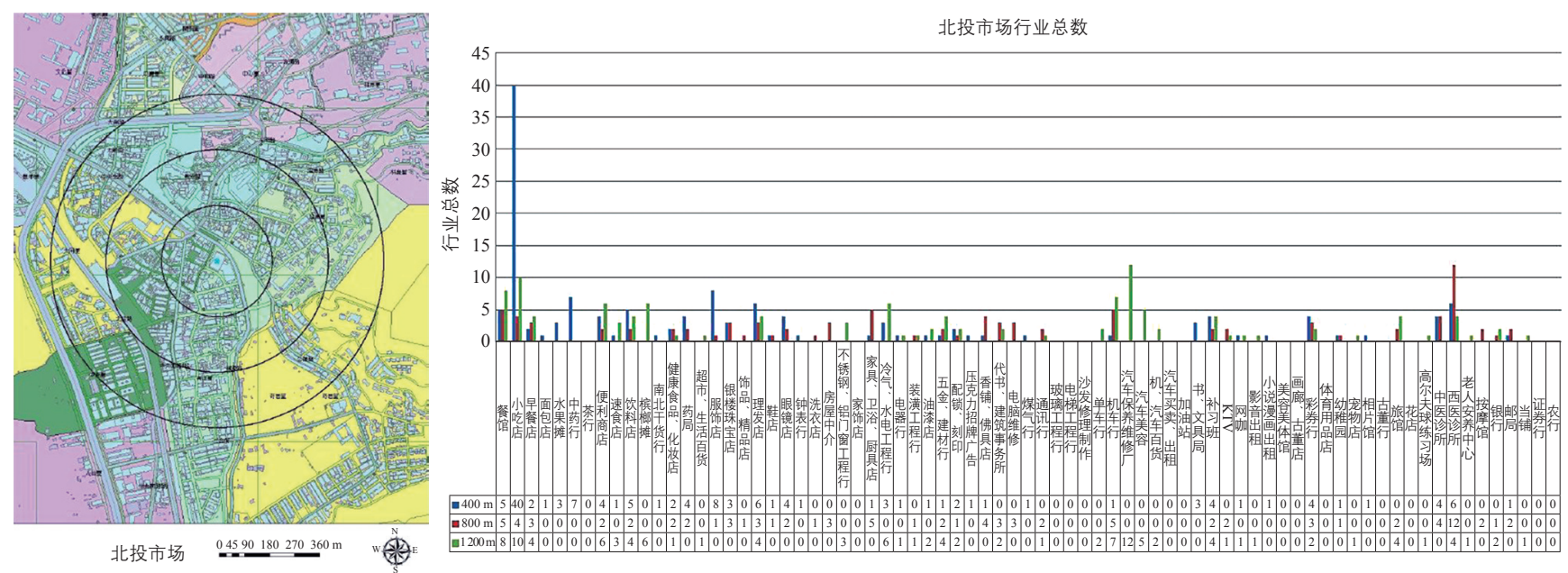

图 3 台北北投市场消费圈范围 (左) 和行业总数 (右)

资料来源 : 参考文献 [20]

(1) 小贩中心分为三种类型: (1) MHC, 包括巴刹和熟食中心; (2) HC, 仅包括熟食中心; (3) MK, 仅包括巴刹。巴刹一词来自马来语, 原来 的拼法是 pasar，意思是市场、集市。有学者考证，“pasar”这个词源自波斯语。 
须是年满 21 岁的新加坡市民或者永久居民 ${ }^{1}$ 。小贩中心已 经成为新加坡民众社区聚会的重要场所和文化认同的一部 分, 2015 年末, 调研显示超过 $73 \%$ 的被访者每周至少去一 次小贩中心 ${ }^{[21]}$ 。

\section{1 发展历程}

与亚洲多数城市一样, 新加坡在历史上也面临过零散商 推占据城市街巷、污染环境、阻碍交通等城市管理难题。殖 民政府的管理尝试鲜有成效。1965 年新加坡独立后, 政府决 定重新安置街头零散商推, 于 1968-1969 年登记商贩、发 放牌照, 将商摊集中到支路、后巷、空停车场等地临时营业, 当时登记在册商贩达 18000 名。1971 年开始, 商贩被迁徙 到政府建立的小贩中心内集中管理，有营业执照的商贩可从 小贩中心租赁到租金优惠的商推, 享受用水和废弃物处理等 服务, 遵守规定按时定点经营。

小贩中心作为邻里中心的重要功能伴随 20 世纪 70 年代 新镇的规划建设迅速涌现。至 20 世纪 80 年代中期, 商贩迁 徙计划基本完成，共有 140 个小贩中心运营。新加坡政府一 度认为巴刹营业时间短, 不符合现代人的生活需求, 于是从 1985 年起不再建设巴刹和熟食中心二合一的小贩中心 ; 之 后因民间请愿，改为由建屋局兴建、私人投标经营的模式， 租约为 30 年。 20 世纪 90 年代中期共建设了 14 个私营巴刹。

新加坡于 2001 年推出 “小贩中心提升计划” (HUP: Hawker Centres Upgrading Programme), 由政府出资加固结构, 改善硬件设施。从 2011 年起, 政府计划在未来 10 年新建 10 个小贩中心。

\section{2 规划布局 : 结合邻里中心规划}

兴起之初, 市中心区的小贩中心选点在居住区周围, 目 的是接近原来零散商贩售卖的地方, 方便新老顾客; 此外, 更多的小贩中心（约 70\%）集中在新镇。新镇的配套设施 随着 20 世纪 70 年代邻里中心的设立得以逐步改善, 新兴 的小贩中心便是邻里中心的重要功能之一, 按 $500 \mathrm{~m}$ 服务 半径基本覆盖新镇。小贩中心规模在 1000 1 $500 \mathrm{~m}^{2}$ 之间, 与组屋区同时建设, 商户和居民同时迁人, 既满足了居民买 菜、购物、用餐的需求, 改善了居住环境, 增进了邻里感情, 也提供了更多的就业机会, 成为新镇居民生活的重要公共 空间。

2001 年, 新加坡提出 “小贩中心提升计划”, 计划在未来 13 年内由政府出资 4.2 亿新加坡元（约合 19.8 亿人民币）与 小贩中心的小贩公会合作, 形成改造或者重建方案, 加固 106 个小贩中心的结构, 改善硬件设施。2012 年, 环境局计划到 2027 年新建 20 个小贩中心, 由政府官员、学者、设计师等共 同成立 “小贩中心 3.0 委员会”, 并确定了规划选址, 多在居 住区集中的轨道站点附近, 并尽可能结合公园设置小贩中心

（图 4)。民意调查显示, 超过 94\% 的受访者对提升计划的实 行很满意, 认为有效地提升了饮食环境和用餐体验 ${ }^{[22]}$ 。

除合理设计提升硬件条件外, 提升计划还在市场改造期 间进行了整体性的空间时序安排, 针对符合条件的第一代商 贩、现营商贩和新商贩分别推出了现金补偿、租金调整、档 位调整等过渡措施。另外, 配合 “非营利模式”, 改造期间 还很注意保持食品价格的稳定。
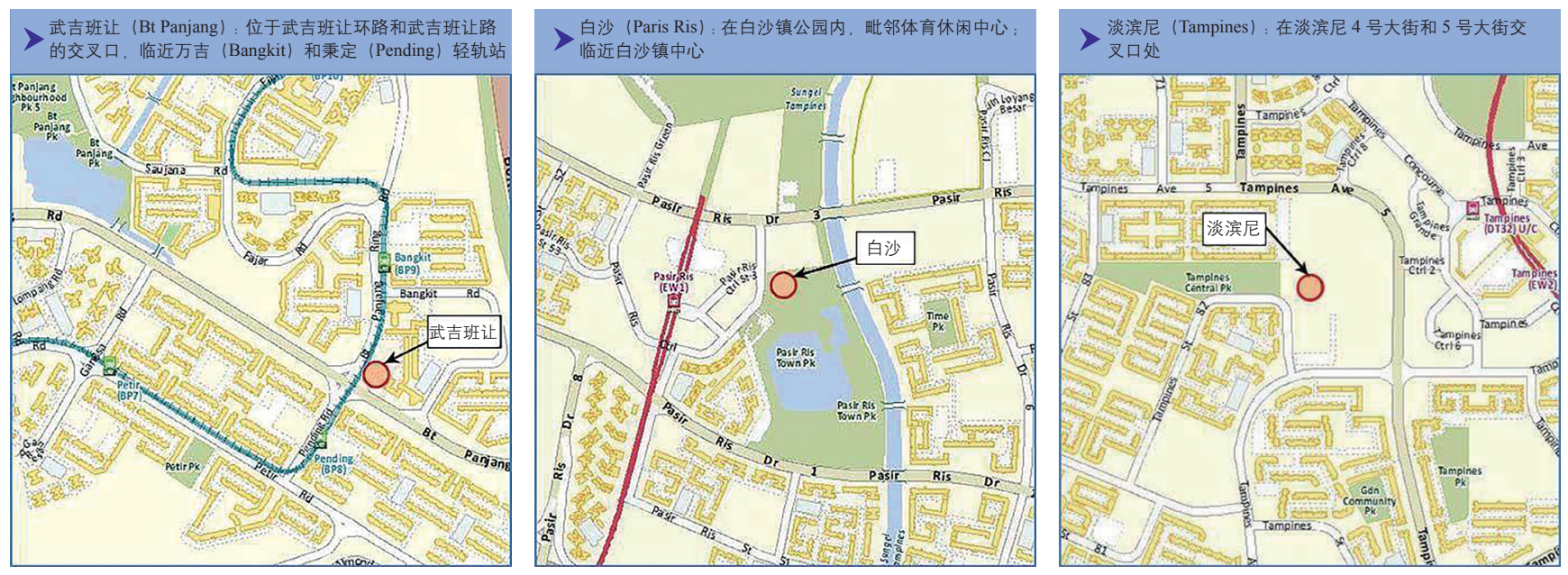

图 4 新加坡新小贩中心选址规划

资料来源 : 参考文献 [23]

(1) 规定详见 National Environment Agency. I Want to be a Stallholder[EB/OL]. [2016-11-20]. https://e-services.nea.gov.sg/hcms/mainpage.aspx. 


\section{3 建筑形式: 灵活多样}

新加坡新镇建设时期的小贩中心以独立建筑为主, 而 到后期小贩中心的建筑形式出现两种新的趋势 : 一种是与其 他功能混合节约用地, 如布置在多层停车场底层; 另一种是 在邻里组团中衍生出小型私营小贩中心。这种小贩中心以售 卖饮料为主, 一般设在组屋楼下, 设 $5 \sim 10$ 个推位, 占地约 $150 \sim 250 \mathrm{~m}^{2}$ 。因为离家近, 小贩中心成为社区居民尤其是老 年人休闲交往的公共空间。1985 年, 随着私人经营的冷气食 阁的出现, 用餐的舒适度进一步提升（图 5)。

\section{4 管理机制：“非营利模式”与小贩公会自治}

新加坡的小贩中心由环境局统一管理 ; 其产权由环境 局、建屋局和裕廊集团三个政府部门所有, 其中建屋局拥 有 $75 \%$ 的小贩中心。建屋局是小贩中心的建设主体和所有 权主体; 环境局小贩署统一对小贩中心进行租赁管理、执 照管理和关系到公众健康的各方面管理, 同时负责小贩中 心的升级 ${ }^{[24]}$ 。为达到可支付目标, 环境局通过调整租金和 制定优惠、补贴政策等措施稳定食物价格。在公建私营时期, 随着获得经营权的公司有权自定租金分租推位, 承租的店 主可转租推位或雇人经营, 一些潜在的社会问题逐渐暴露 出来, 政府最终选择收回管理权, 回归 “非营利模式”, 由 商贩、管理者和环境局利益相关者共享各小贩中心的运营 盈余, 并且用于社会福利 ${ }^{[25]}$ 。
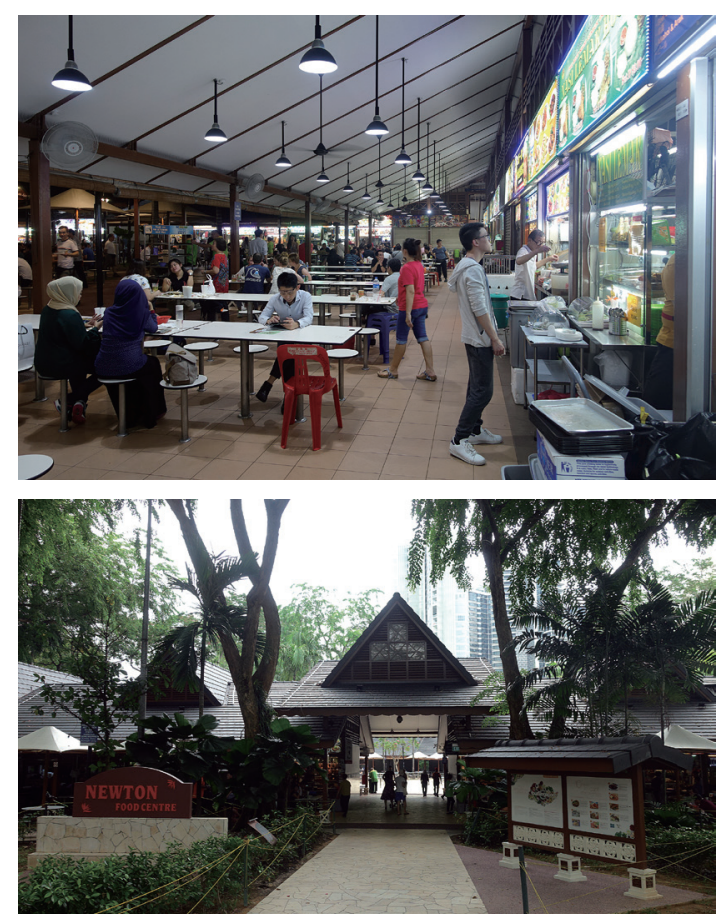

图 5 新加坡牛顿小贩中心 ( Newton Food Center) 资料来源 : 作者拍摄
在政府统一管理之外, 新加坡的小贩中心都设有自治 性质的小贩公会, 与政府管理形成互补。在早期, 小贩公会 主要负责组织商贩合理利用和维护公用设施。在 “小贩中 心提升计划” 中, 小贩公会与政府合作, 共同推动工程实 施。小贩公会的形成与商贩很强的自主权密不可分, 新加坡 政府分别于 1994 年和 1998 年推出 “推位自有计划” (Stall Ownership Scheme) 和 “推位顶让计划” (Stall Assignment

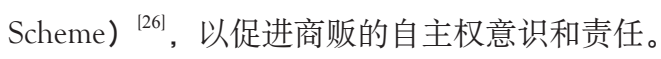

\section{4 经验借鉴}

通过梳理中国香港、中国台湾和新加坡三地菜市场发展 历程可发现, 将菜市场作为公共服务设施设置有三个基本目 的：（1）整治街道公共卫生环境, 把零散商推纳人正规管理 体系；（2）服务附近居民, 满足购菜、用餐需求, 为居民提 供可支付的生鲜食品; (3) 为社区提供就业机会, 尤其是小 贩群体。三地菜市场发展都经历了从零散经营到集中管理、 从快速发展到转型更新的发展阶段, 在集中建设阶段是基本 指导思想和规划原则得以确立的时期, 而转型更新阶段更多 地体现出因地制宜发展的新趋势, 对我国大城市菜市场发展 有如下启示 (表 1)。

表 1 中国香港、中国台湾、新加坡三地菜市场规划建设管理经验总结

\begin{tabular}{|c|c|c|c|}
\hline & 香港 & 台湾 & 新加坡 \\
\hline $\begin{array}{l}\text { 市场 } \\
\text { 规划 }\end{array}$ & $\begin{array}{l}\text { 没有强制条款, 有 } \\
\text { 参考标准和用地类 } \\
\text { 型限定, 根据需求 } \\
\text { 进行规划审批 }\end{array}$ & $\begin{array}{l}\text { 政府主导 ; 市场作 } \\
\text { 为公共设施之一, } \\
\text { 划定“市场用地” }\end{array}$ & $\begin{array}{l}\text { 新镇邻里中心的重要组成 } \\
\text { 部分; 作为地块再开发要 } \\
\text { 求之一 }\end{array}$ \\
\hline $\begin{array}{l}\text { 政策 } \\
\text { 条例 }\end{array}$ & $\begin{array}{l}\text { 香港规划标准与 } \\
\text { 准则 }\end{array}$ & $\begin{array}{l}\text { “都市计划法” / 零 } \\
\text { 售市场管理条例 }\end{array}$ & $\begin{array}{l}\text { 环形城市和新镇建设空间模 } \\
\text { 式下的商业网点规划 }\end{array}$ \\
\hline $\begin{array}{l}\text { 设置 } \\
\text { 标准 }\end{array}$ & $\begin{array}{l}55 \sim 65 \text { 户 / 档 位, } \\
\text { 或者 40 45 档位 / } \\
\text { 万人 (1990 年) }\end{array}$ & $\begin{array}{l}\text { 按问邻单位或居民 } \\
\text { 分布情形适当配置 }\end{array}$ & $\begin{array}{l}\text { 邻里中心服务 } 6000 \text { 8000 住 } \\
\text { 户, } 500 \mathrm{~m} \text { 服务半径; 考虑 } \\
\text { 需要迁置商贩数量 }\end{array}$ \\
\hline $\begin{array}{l}\text { 建筑 } \\
\text { 形式 }\end{array}$ & $\begin{array}{l}\text { 结合市政大厦（位 } \\
\text { 于一、二、三层） }\end{array}$ & $\begin{array}{l}3 \sim 4 \text { 层 的 现 代 综 } \\
\text { 合楼 (市场在一、 } \\
\text { 二层) }\end{array}$ & $\begin{array}{l}\text { 早期结合邻里中心独立地 } \\
\text { 块, 后期多与其他功能混合 } \\
\text { 如结合政府大楼、停车场等 }\end{array}$ \\
\hline $\begin{array}{l}\text { 市场 } \\
\text { 规模 }\end{array}$ & $1000 \sim 3000 \mathrm{~m}^{2}$ & $1000 \sim 2000 \mathrm{~m}^{2}$ & $1000 \sim 1500 \mathrm{~m}^{2}$ \\
\hline $\begin{array}{l}\text { 所有 } \\
\text { 权 }\end{array}$ & $\begin{array}{l}\text { 由公营服务主导转 } \\
\text { 向市场导向的公营 } \\
\text { 和私营结合 }\end{array}$ & $\begin{array}{l}\text { 公有市场归政府所 } \\
\text { 有, 民有市场归民 } \\
\text { 间所有 }\end{array}$ & $\begin{array}{l}\text { 分属环境局、建屋局和裕廊 } \\
\text { 集团三个政府部门所有 }\end{array}$ \\
\hline $\begin{array}{l}\text { 建设 } \\
\text { 出资 }\end{array}$ & $\begin{array}{l}\text { 主要由政府出资 } \\
\text { 建设 }\end{array}$ & $\begin{array}{l}\text { 公有市场政府出 } \\
\text { 资, 民有市场民间 } \\
\text { 出资 }\end{array}$ & 建屋局出资建设 \\
\hline $\begin{array}{l}\text { 管理 } \\
\text { 模式 }\end{array}$ & $\begin{array}{l}\text { 政府街市部分由直 } \\
\text { 接管理转向外包多 } \\
\text { 元管理 }\end{array}$ & $\begin{array}{l}\text { 政府主管机关和市 } \\
\text { 场自治组织（管理 } \\
\text { 委员会） }\end{array}$ & $\begin{array}{l}\text { 环境局小贩署主管, 各小贩 } \\
\text { 中心的小贩公会自治 }\end{array}$ \\
\hline
\end{tabular}

资料来源 : 作者根据相关文献整理 


\section{1 规划布局 : 划定专门用地, 依据居民需求设置}

在规划布局方面, 首先应在城市规划中明确菜市场用地 性质。总结东亚经验发现, 中国台湾通过“立法”明确了传 统零售市场的公共属性, 并设置专门的用地类型, 保障了足 量实体空间的供应 ; 新加坡把小贩中心作为邻里中心或者再 开发项目的重要组成部分打包考虑, 在前期策划中予以重视; 中国香港主要在规划审批阶段进行控制, 可在图则中规定市 场用途。因此，我国大城市在新建社区时应在策划、规划、 审批过程中明确要求配建菜市场, 并切实落实用地; 对于缺 乏菜市场的老旧社区, 可借助城市更新契机参考新加坡经验, 采取灵活多样的建筑形式。

其次, 菜市场的设置标准应根据居民需求确定, 并综 合考虑商贩的安置问题。我国现行居住区规范主要依据 “千 人指标” 来配置菜市场面积, 受到单个居住小区开发地块 的限制, 形成了中小规模菜市场分散布置的形态; 而东亚 三地菜市场多设置在居住单元这一中间层级，由若干个小 居住单元共享一个集中的较大规模的菜市场。后者实则是 更高效的方式，可满足居民一站式购物的需求。与此同时， 与驱逐打击不同，三地政府选择给予商贩合法的空间，中 国香港和新加坡还会着重考虑根据需要迁置的商贩数量确 定市场规模。虽然新加坡的商贩以本地人为主, 有其特殊性, 与我国大城市商贩以外来人口为主的结构不同, 但是从建 设包容性城市角度出发, 仍应对商贩安置有所考虑。另外, 对于规范不适用的老旧小区, 三地经验是进人更新改造阶 段后, 新设菜市场不依靠硬性指标, 而是根据实际诉求灵 活选址、查漏补缺。

\section{2 建筑设计 : 混合功能、立体发展和提高空间品质}

在建筑设计方面，首先建议将菜市场与社区中心等多种 功能立体组合, 提高土地利用效率。在我国大城市, 菜市场 屡遭拆除取缔的两个重要原因是菜市场用地效率低、建筑空 间环境差。三地经验表明，功能混合是提升活力、节约用 地的绝佳选择，市政办公、社区康乐、公共图书馆、幼儿 园、交通站点和停车场等多种功能都可与菜市场结合。中 国香港多采取中高层的市政大厦形式, 街市转人室内的一、 二层; 中国台湾则采用中低层的综合楼形式 ; 新加坡在新 镇建设时采用的是平面混合形式，而后又发展为垂直混合， 建设于商业和交通设施等用地上，有的甚至与国家发展部 大楼结合。这种与社区中心结合的菜市场建设模式, 既能 给居民生活带来便利，又能创造富有生活气息的邻里空间。 我国大城市在建设菜市场时可结合社区功能需要灵活选择 建筑形式。

此外, 还应通过加强管理和提升服务, 改善菜市场的空
间环境，营造活力的市场文化。中国香港推行 “每月街市清 洁日” 以保持整洁, 同时采取活化措施与公共空间衔接; 新 加坡邀请知名设计师改造、新建小贩中心, 媲美地标建筑; 中国台湾则结合市场举办文化活动。此外, 在欧洲还出现将 菜市场更新作为城市文化复兴引擎的趋势, 例如荷兰鹿特丹 的 Markthal 菜市场、西班牙巴塞罗那的 Santa Caterina 市场等, 凸显了菜市场在城市、街区和邻里的文化意义。这些做法都 值得借鉴参考。

\section{3 管理机制：政府主导与市场自治结合}

在管理机制方面, 首先建议由政府主导管理作为公共服 务配套的菜市场。菜市场与公共卫生、居民生活密切相关, 属于公共服务的重要内容, 这是东亚三地政府的共识。三地 在菜市场规划起初, 政府都是最主要的所有者、建设者和经 营者, 随着时代发展, 各地对菜市场的经营权和所有权进行 了不同的探索。中国香港街市私有化暴露出市场经营的弊端。 中国台湾传统零售市场从建立之初即鼓励民间投资，民有市 场自有产权; 公有市场尝试业务外包, 但所有权没有变更。 新加坡政府一直持有小贩中心的所有权, 并在新建计划中强 调由政府管理, 采取 “非营利模式”。由于菜市场带有明显 的负外部性, 经济效益有限, 采取市场化的私营或私有行为 虽然有利于充分竞争, 可以快速应对现代化生活的新需求, 但与此同时, 放任其市场化又存在引发社会矛盾的风险, 由 于企业逐利的本质，难免导致租金和菜价的上涨，从而抬高 商贩和居民的生活成本。因此如何在活跃菜市场的同时适当 管控企业行为是关键, 需要坚守的底线在于不违背提供可支 付的公共服务的初衰。从实施效果来看, 新加坡由政府发挥 主导作用的 “非营利模式”值得借鉴。

其次, 应注重市场自治力量的培育, 这于商贩而言有利 于自我管理，于民众而言有利于稳定生活。在中国香港街市 兴建和活化更新的各个阶段, 都可以看到社区自组织的出现, 议员、社会活动家和普通民众为保存街市记忆与开发商博弯。 中国台湾零售市场的自治组织内形成了约定俗成的自我管理 机制, 在促进市场卫生、规范, 形成良好的公众形象方面发 挥了很大作用。在新加坡, 小贩公会最初的合作促成了种族 的融合和社会的团结 ${ }^{[26]}$ 。菜市场与公众、商贩的切身利益相 关, 在日常运营应注重市场自治力量的培育, 充分发挥其主 观能动性。 UP

感谢清华大学毛其智教授对本文写作的指导。感谢清华大 学 SRT 项目“北京城乡便民服务设施现状问题与规划对策研 究”（1421T0394）课题组成员姜行健、罗又源、邓秋实、王敏 钊和邓晨阳在本文前期研究中的工作。 


\section{参考文献}

[1] 柴定红. 上海非正规经济发展对农民工就业空间的挤压 [J]. 社会, 2003(9): 8-9.

[2] Zhang Q F, Pan Z. The Transformation of Urban Vegetable Retail in China: Wet Markets, Supermarkets and Informal Markets in Shanghai[J]. Journal of Contemporary Asia, 2013, 43(3): 497-518.

[3] 张杰, 杨阳, 毛其智. 居住区不同服务设施类型重要性比较研究 [J]. 住 区, 2013(2): 142-147.

[4] 陈宇琳. 北京望京地区农贸市场变迁的社会学调查 [J]. 城市与区域规 划研究, 2015(2): 73-99.

[5]陈宇琳. 特大城市外来自雇经营者的市民化机制研究——基于北京南 湖大棚市场的调查 [J]. 广东社会科学, 2015(2): 204-213.

[6] Goldman A, Frider R, Ramaswami S. The Presistent Competitive Advantage of Traditional Food Retailers in Asia: Wet Markets' Continued Dominance in Hong Kong[J]. Journal of Macromarketing, 1999, 19(2): 126-139.

[7] 香港规划署.香港规划标准与准则. 2009 年修订 [S/OL]. (2009)[2016-06-28]. http://www.pland.gov.hk/pland_tc/tech_doc/hkpsg/full/ch6/ch6_text.htm.

[8] 香港特别行政区政府食品环境卫生署. 公众街市概览 [EB/OL]. (201601-01)[2016-06-26]. http://www.fehd.gov.hk/tc_chi/pleasant_environment/ tidy_market/overview.html.

[9]香港审计署. 关于食物及卫生局食物环境卫生署公众街市的管理报告 [R/OL]. (2008-10-23) [2016-06-27]. http://www.aud.gov.hk/pdf_c/c51ch06. pdf.

[10] 房屋及规划地政局. 立法会房屋事务委员会分拆出售房屋委员会的零 售和停车场设施 [EB/OL]. (2003-10)[2016-06-27]. http://www.legco.gov. hk/yr03-04/chinese/panels/hg/papers/hg1103cb1-190-4c.pdf.

[11] 尔东, 何泳仪, 张淑茵。许嘉淇摄影。乐游香港街市 [M]. 香港: 明报出 版社, 2015 .

[12] 刘卫斌, Jens Schott Knudsen. 香港 “街市” 的死去与活来 [J]. 世界建筑 导报, 2013(1): 22-23.

[13] HKCC: Hong Kong Consumer Council. Grocery Market Study Market Power of Supermarket Chains Under Scrutiny [R/OL]. (2013-12-19)[201606-28]. https://www.consumer.org.hk/sites/consumer/files/competition_ issues/20131219/GMSReport20131219.pdf.

[14] 运输及房屋局, 食物及环境卫生局。香港立法会房屋事务委员会 2015 年 12 月 7 日的会议 [EB/OL]. (2016-04-05)[2016-06-29]. http://www.legco, gov.hk/yr15-16/chinese/panels/hg/papers/hg20151102cb1-752-1-c.pdf.

[15] Chan Y. The Future of Graham Street Market[J/OL]. HK-Magazine. (201310-31)[2016-06-29]. http://hk-magazine.com/article/11533/future-grahamstreet-market.

[16] “台湾经济部”.98-99 年传统零售市场更新改善计划执行成果汇编 [R/ OL]. (2011-01)[2016-07-03]. http://www.cto.moea.gov.tw/04/word/04-2.pdf.

[17] 吴郑重。“菜市场”的日常生活地理学初探: 全球化台北与市场多样 性的生活城市省思 [J]. 台湾社会研究, 2004(9): 47-99.

[18] 李常生, 董卫. 台湾城市中传统零售（菜）市场与推贩的现代化方案 探讨 [J]. 现代城市研究, 2007(5): 62-69.

[19] 福建日报. 菜市场玩 style 的背后 [N/OL]. (2013-03-18)[2016-07-03]. http://www.chinanews.com/tw/2013/03-18/4652769.shtml.

[20] 郭明璋. 从活动多样性观点, 探究台北市北投区邻里中心空间组成模 式 [D]. 中国文化大学硕士论文, 2011: 47-48.

[21] NEA: National Environment Agency. Committee Set Up to Review Singapore's Hawker Centres and Hawker Trade[EB/OL]. (2016-04-17) [2016-07-13]. http://www.nea.gov.sg/corporate-functions/newsroom/newsreleases/committee-set-up-to-review-singapores-hawker-centres-and-hawkertrade2.

[22] NEA.The Story of Hawker Centres Upgrading Programme (HUP)[EB/OL]. (2016-04-17)[2016-07-14]. http://www.nea.gov.sg/public-health/hawkercentres/the-story-of-hawker-centres-upgrading-programme-\%28hup\%29.

[23] NEA. New Hawker Centres[EB/OL]. (2016-04-17)[2016-07-14]. http://www. nea.gov.sg/corporate-functions/newsroom/parliament/budget-debate1/ budget-debate-2012/hawker-centres.
[24] NEA. Managing Hawker Centres and Markets in Singapore[EB/OL]. (201604-17)[2016-07-14]. http://www.nea.gov.sg/public-health/hawker-centres/ managing-hawker-centres-and-markets-in-singapore.

[25] Feng Zengkun. Hawkers Unsure of Not-for-profit Model[EB/OL]. (2014-0113)[2016-07-14]. http://www.straitstimes.com/singapore/hawkers-unsure-ofnot-for-profit-model.

[26] Gannon Martin J. Understanding Global Cultures: Metaphorical Journeys Through 28 Nations, Clusters of Nations, and Continents[M]. SAGE Publications, Inc., 2003: 403-404.

(本文编辑：王枫) 